\title{
Infrared Spectroscopic and Density Functional Theory Investigations of PdTi Heterodimer Reactivity with Carbon Monoxide Isolated in Solid Argon
}

\author{
M. Ibrahim, P. Soulard, E. Alikhani*, and B. Tremblay* \\ Sorbonne Université, CNRS, UMR 8233, MONARIS, Case courrier 49, 4 place Jussieu, F-75005, Paris, \\ France
}

\begin{abstract}
The reactivity of diatomic palladium-titanium toward carbon monoxide has been studied in solid argon by infrared spectroscopy (FTIR) in the carbonyl stretching frequency region. Our technique of sublimation of Ti and Pd atoms from two filaments heated separately allowed the identification of five new molecules. Small polynuclear carbonyl clusters, $\operatorname{PdTi}(C O)_{n}(n=1-3)$ have been characterized on the basis of isotopic substitutions, metal atoms and $\mathrm{CO}$ concentration variations and irradiation effects. Selective irradiation in visible leads to conversion between two isomers distinguished by the stretching frequency of the diatomic CO: PdTiCO Ti-eo $\left(v_{\mathrm{CO}}=1908.4 \mathrm{~cm}^{-1}\right)$ and PdTiCO Pd-eo $\left(v_{\mathrm{CO}}=2009.3 \mathrm{~cm}^{-1}\right)$. The Density Functional Theory (DFT) calculations have been carried out to elucidate the geometrical and electronic structures and support the spectral assignments. The nature of the metal-carbon bonding has been discussed using the topology of the Laplacian of the electron density.
\end{abstract}

*Author to whom correspondence should be addressed.

E-mail:esmail.alikhani@sorbonne-universite.fr, Tel :33144273072; benoit.tremblay@sorbonne-universite.fr, Tel : 33144273835

\section{INTRODUCTION}

Bimetallic catalysts have attracted great research efforts in the past decades due to their chemical and physical properties different from the individual pure metals and promising applications in chemical conversion, energy technology and environmental protection ${ }^{1-4}$. Since a lot of studies are interested in all 
these important applications, numerous experimental and theoretical investigations have been focused on the reactions of transition metal atoms and small clusters with carbon monoxide and a variety of transition-metal carbonyl molecules have been characterized ${ }^{5-10}$. Rare gas matrix isolation is a well established technique used to stabilize small metal molecules and clusters in large enough quantities to enable detection by electronic or vibrational spectroscopy ${ }^{11}$, thus providing a first approach to investigate the atomic or molecular reactivities, complementary or preliminary to gas-phase investigations. ${ }^{12-13}$ Recently, many works have been reported on polynuclear carbonyls by trapping evaporated $\mathrm{M}$ atoms with carbon monoxide in solid argon. As an example, some small metal cluster carbonyls, such as $\mathrm{Co}_{2} \mathrm{CO}^{14}, \mathrm{Fe}_{2} \mathrm{CO}^{15}, \mathrm{Ti}_{2}(\mathrm{CO})_{\mathrm{n}}$ $(\mathrm{n}=1,2)$ and $\mathrm{Ti}_{3}(\mathrm{CO})_{\mathrm{n}}(\mathrm{n}=1-3)^{16}, \quad \mathrm{M}_{2} \mathrm{CO}(\mathrm{M}=\mathrm{Sc}, \mathrm{Y} \text { and } \mathrm{La})^{17-19},(\mathrm{AgCO})_{2}$ and $\mathrm{Ag}_{\mathrm{n}} \mathrm{CO}(\mathrm{n}=2-4)^{20}, \mathrm{Au}_{\mathrm{n}} \mathrm{CO}$ $(\mathrm{n}=1-5)$ and $\mathrm{Au}_{2}(\mathrm{CO})^{21}$ have been synthesized and characterized by infrared spectroscopy in the carbonyl stretching frequency region ${ }^{14-21}$ and in the far infrared ${ }^{14-15}$.

In our laboratory, by coupling matrix isolation FTIR spectroscopy and DFT calculations, the molecules $\mathrm{Pd}_{2} \mathrm{~N}_{2}^{22}$ then $\mathrm{Pd}_{2} \mathrm{CO}^{23}$ isolated in solid argon and neon were characterized. There are strong similarities between these two molecules since the ground state corresponds to the ligand bridged (br) on the two Pd atoms, $\operatorname{Pd}_{2}\left(\eta^{2}-\mathrm{L}\right)$, with a $\mathrm{C}_{2 \mathrm{v}}$ symmetry. In argon we observed another isomer with the ligand in terminal position (end on, eo), $\mathrm{Pd}_{2}\left(\eta^{1}-\mathrm{L}\right)$, with a frequency of about $180 \mathrm{~cm}^{-1}$ higher than the $\mathrm{C}_{2 \mathrm{v}}$ form. By selective irradiations in the visible, it is possible to convert the molecules of the terminal form to bridged form.

On the other hand, using laser-ablation method for producing metal atoms, Andrews and co-workers showed that titanium atoms react readily with $\mathrm{CO}$ molecules in $\operatorname{argon}^{7}$ and neon ${ }^{8}$, and infrared spectroscopic evidence with ${ }^{13} \mathrm{CO}$ and $\mathrm{C}^{18} \mathrm{O}$ substitution is presented for the identification of $\mathrm{Ti}(\mathrm{CO})_{\mathrm{n}}$ species $(\mathrm{n}=1-6)$. But using thermal evaporation for producing metals atoms, Manceron and co-workers did not observe the band assigned to $\mathrm{TiCO}$ in neon, and they have observed the $\mathrm{Ti}_{2} \mathrm{CO}$ molecule ${ }^{24}$. More, $\mathrm{Xu}$ and co-workers reported the FTIR spectroscopic characterization and theoretical investigation of side-on-bonded mono and polycarbonyl titanium clusters $\mathrm{Ti}_{2}(\mathrm{CO})_{\mathrm{n}}(\mathrm{n}=1,2)$ and $\mathrm{Ti}_{3}(\mathrm{CO})_{\mathrm{n}}(\mathrm{n}=1-3)^{16}$. Another work has experimentally shown that the Ti dimer spontaneously reacts with $\mathrm{N}_{2} \mathrm{O}$ molecule leading to the formation of an adduct 
complex, $\mathrm{OTi}_{2} \mathrm{~N}_{2}$. Irradiation in the near infrared region results to the $\mathrm{N} \equiv \mathrm{N}$ bond breaking and then the formation of a new molecule, OTiNTiN ${ }^{25}$.

Concerning the heteronuclear carbonyl molecules, many works have been done on bimetallic carbonyl anions and cations in the gas phase. Mass-selected $\mathrm{CuFe}(\mathrm{CO})_{\mathrm{n}}{ }^{-}(\mathrm{n}=4-7), \mathrm{FeM}(\mathrm{CO})_{8}{ }^{+}(\mathrm{M}=\mathrm{Co}, \mathrm{Ni}$ and $\mathrm{Cu})$, $\mathrm{MCu}(\mathrm{CO})_{7}{ }^{+}(\mathrm{M}=\mathrm{Co}$ and $\mathrm{Ni}), \mathrm{FeZn}(\mathrm{CO})_{5}{ }^{+}$, and $\mathrm{CoZn}(\mathrm{CO})_{7}{ }^{+}$molecules have been studied by infrared photodissociation spectroscopy in the carbonyl stretching frequency region ${ }^{26-28}$. The geometric and electronic structures of these ions are assigned with the support of density functional calculations. Also, a series of heteronuclear metal carbonyl anions have been investigated using photoelectron velocity-map imaging spectroscopy: $\mathrm{CuNi}(\mathrm{CO})_{\mathrm{n}}{ }^{-}(\mathrm{n}=2-4), \mathrm{MNi}(\mathrm{CO})_{3}{ }^{-}(\mathrm{M}=\mathrm{Mg}, \mathrm{Ca}, \mathrm{Al}), \mathrm{MNi}(\mathrm{CO})_{\mathrm{n}}{ }^{-}(\mathrm{M}=\mathrm{Ti}, \mathrm{Zr}, \mathrm{Hf} ; \mathrm{n}$ $=3-7), \operatorname{AgNi}(\mathrm{CO})_{\mathrm{n}}{ }^{-}(\mathrm{n}=2,3), \mathrm{V}_{2} \mathrm{Ni}(\mathrm{CO})_{\mathrm{n}}{ }^{-}(\mathrm{n}=6-10)$, and $\mathrm{VNi}(\mathrm{CO})_{\mathrm{n}}{ }^{-}(\mathrm{n}=2-6)^{29-34}$. In these works, the electron affinities, the $\mathrm{C}-\mathrm{O}$ stretching modes, and the vertical detachment energies are measured (all the parameters are not determined in each work).

The purpose of the present work is to extend the study of the reactivity of the neutral homonuclear dimer to heteronuclear dimer. We report for the first time the reaction of the PdTi heterodimer with $\mathrm{CO}$ in solid argon and the formation of $\operatorname{PdTi}(C O)_{n}(n=1-3)$ and $\operatorname{Pd}_{x} \operatorname{Ti}_{y}(C O)_{2}$, neutral molecules. Each metal is vaporized separately and the PdTi formation occurs in the matrix. We investigated these carbonyl complexes using infrared spectroscopy combined with density functional calculations to obtain the geometrical and electronic properties. The system $\mathrm{Pd}+\mathrm{Ti}$ has been chosen for the fact that the reactivity of the Ti+CO ${ }^{7,8,16,24}$ and $\mathrm{Pd}+\mathrm{CO}^{9,10,23}$ systems has been examined in $\mathrm{Ar}$ or Ne matrix giving a first approach to the spectral analysis.

\section{EXPERIMENTAL AND COMPUTATIONAL DETAILS}

The experimental setup for matrix isolation FTIR spectroscopic investigation has been described in detail previously ${ }^{35}$. Briefly, the samples were prepared by co-condensing Ti and Pd vapors and CO-Ar mixtures $(0.1-4 \% \mathrm{CO}$ in $\mathrm{Ar})$ onto one of six flat, highly polished, Rh-plated copper mirrors maintained at 12 K or $20 \mathrm{~K}$ using a closed cycle cryogenerator (model PT405, Cryomech, Syracuse, NY, USA) situated in a stainless-steel cell evacuated at a pressure less than $5 \times 10^{-7}$ mbar. A tungsten or tantalum filament, mounted 
in a furnace assembly and wetted with palladium (Alpha Inorganics, 99.9\%), was heated from 1200 to $1400^{\circ} \mathrm{C}$ to generate $\mathrm{Pd}$ vapor and a Ti-Mo filament (Goodfellow, $85 \% \mathrm{Ti}$ ) was heated at about $1500^{\circ} \mathrm{C}$ to generate Ti vapor. For the first time the two metals are evaporated separately, each filament is mounted on two electrodes in the furnace. The metals deposition rate was carefully monitored with the aid of a quartz microbalance and was typically of the order of $1-10 \mu \mathrm{g} \mathrm{min}^{-1}$. High-purity argon (Prodair; 99.995\%), carbon monoxide (Matheson; 99.5\%), ${ }^{13} \mathrm{C}^{16} \mathrm{O}$ (CEA, Saclay, France, $99 \%{ }^{13} \mathrm{C}^{16} \mathrm{O}$ including $9 \%{ }^{13} \mathrm{C}^{18} \mathrm{O}$ ), and ${ }^{12} \mathrm{C}^{18} \mathrm{O}\left(\mathrm{MSD} ; 98 \%{ }^{18} \mathrm{O}\right.$ ) were used to prepare the $\mathrm{CO}-\mathrm{Ar}$ mixtures after removing condensable impurities with a liquid- $\mathrm{N}_{2}$ trap.

In general, after deposition times varying between 15 and 90 min, infrared spectra of the sample were recorded at $0.1 \mathrm{~cm}^{-1}$ resolution in the transmission-reflection mode between 4000 and $70 \mathrm{~cm}^{-1}$ using a Bruker 120 FTIR spectrometer and suitable combinations of $\mathrm{CaF}_{2} / \mathrm{Si}, \mathrm{KBr} / \mathrm{Ge}$, Si/Mylar $(6 \mu \mathrm{m})$ beamsplitters with either liquid $\mathrm{N}_{2}$-cooled $\mathrm{InSb}$ or narrow-band $\mathrm{HgCdTe}$ photodiodes or a liquid $\mathrm{He}$-cooled $\mathrm{Si}$-B bolometer fitted with cooled bandpass filters. Bare mirror backgrounds were used as references for processing the sample spectra. Also, absorption spectra in the near, mid- and far infrared were collected on the same samples through either $\mathrm{CaF}_{2}$, $\mathrm{CsI}$ or polyethylene windows mounted on a rotatable flange separating the interferometer vacuum $\left(10^{-3} \mathrm{mbar}\right)$ from the cryostatic cell $\left(10^{-7} \mathrm{mbar}\right)$. The spectra were subsequently subjected to baseline correction to compensate for infrared light scattering and interference patterns. The sample was next either annealed in order to increase the abundance of aggregates (if necessary) or irradiated at various wavelength using broad or narrow band-pass filters with a $200 \mathrm{~W} \mathrm{Hg-Xe} \mathrm{high-}$ pressure arc lamp. The most significant results only will be described below.

Molecular geometries were optimized using the DFT B3LYP method with a correlation consistent basis set of triple-zeta quality (cc-pVTZ) for C, O and Ti atoms and the cc-pVTZ-PP basis set with extended relativistic pseudo-potentials for Pd obtained from the Basis Set Exchange (BSE) software and the EMSL Basis Set Library. ${ }^{36-37}$ All calculations have been performed with the Gaussian 09 quantum chemical package. ${ }^{38}$ Vibrational frequeny analysis has been done within the harmonic approximation. The nature of chemical bonds between metal-metal and metal-ligand has been investigated using the QTAIM topological approach $^{39}$ with the AIMALL software. ${ }^{40}$ 


\section{EXPERIMENTAL RESULTS}

Palladium and titanium vapor were condensed with relatively dilute mixtures of $\mathrm{CO}$ in argon $(0.1 \%)$ at $20 \mathrm{~K}$ or at $12 \mathrm{~K}$ but at higher $\mathrm{CO}$ concentration (between 0.5 and $2 \%$ ). In the Figure 1, the first spectrum presents the result for the $\mathrm{Ti}+\mathrm{CO}$ reaction (Figure 1a). We observe a band at $1769.1 \mathrm{~cm}^{-1}$ assigned to $\mathrm{Ti}_{2}(\mathrm{CO})_{2}$ and some bands assigned to $\mathrm{Ti}_{\mathrm{x}}(\mathrm{CO})_{\mathrm{y}}$ species ${ }^{7}$. For the $\mathrm{Pd}+\mathrm{CO}$ reaction (Figure $1 \mathrm{~b}$ ), we observe several bands, two at 1856.5 and $1867.9 \mathrm{~cm}^{-1}$ assigned to $\mathrm{Pd}_{2} \mathrm{CO}$ (br), and a band at $1729.4 \mathrm{~cm}^{-1}$ assigned to $\mathrm{Pd}_{3} \mathrm{CO}^{23}$. For Pd and Ti vaporized together with $\mathrm{CO}$ (Figure 1c), and by comparison with Fig.1a and 1b, we detect five new absorptions at 2009.3, 1908.4, 1808.9, 1790.7, 1745.3, and a broad one at $1718.9 \mathrm{~cm}^{-1}$ (Table 1). The new absorptions shown in figure 1.c are indicated by arrows.

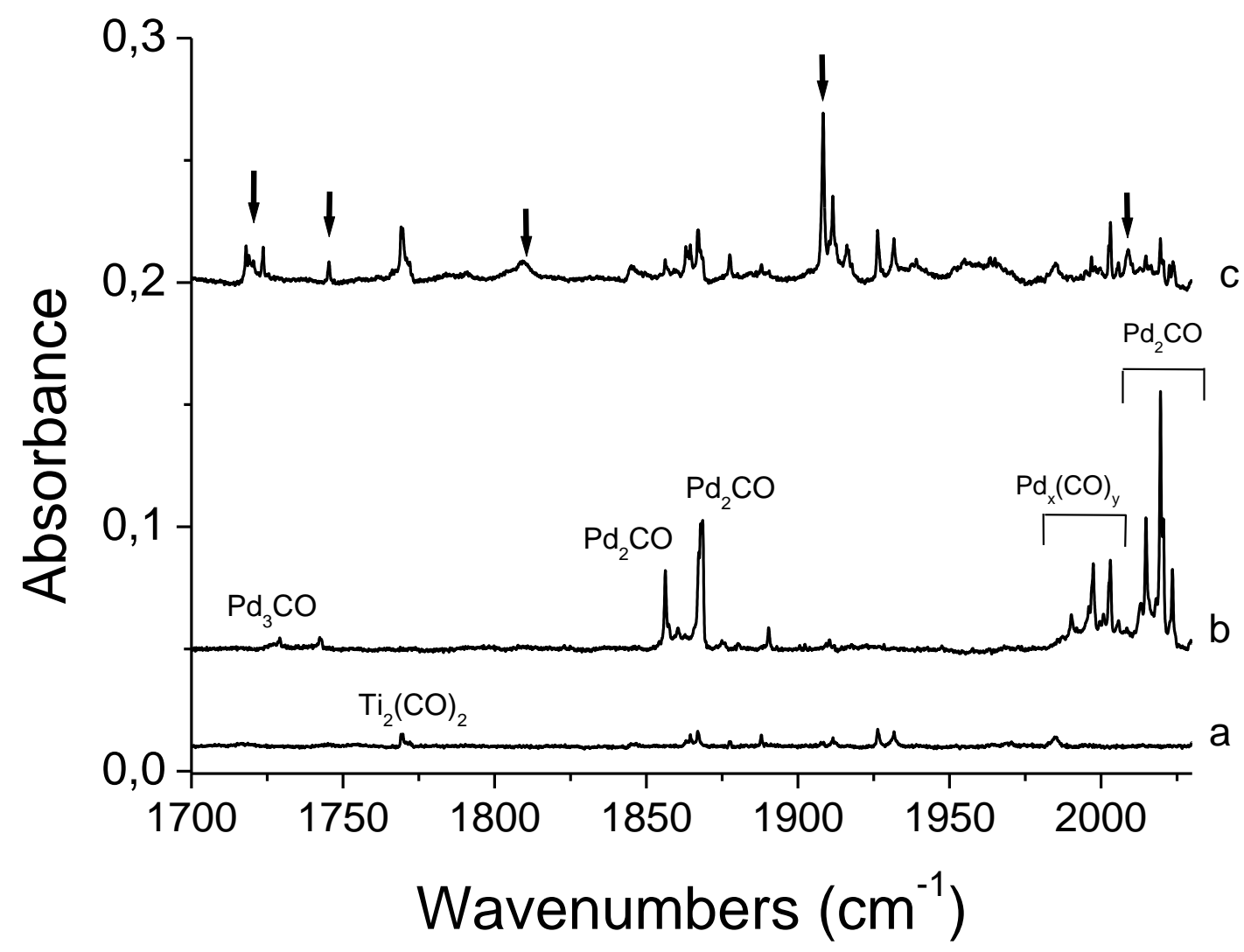

Figure 1. Infrared spectra of titanium, palladium, and palladium-titanium CO reactions after deposition at 12 K. (a) Ti/CO/Ar=0.4/5/1000, (b) $\mathrm{Pd} / \mathrm{CO} / \mathrm{Ar}=0.4 / 5 / 1000$, and (c) $\mathrm{Pd} / \mathrm{Ti} / \mathrm{CO} / \mathrm{Ar}=0.3 / 0.5 / 2 / 1000$. 
Table 1. Experimental vibrational frequencies $\left(\mathrm{in}^{-1}\right)$ and isotopic shifts for the observed molecules

\begin{tabular}{|c|c|c|c|c|c|c|c|}
\hline molecules & assignment & ${ }^{12} \mathrm{C}^{16} \mathrm{O}$ & ${ }^{13} \mathrm{C}^{16} \mathrm{O}$ & $\Delta v^{\mathrm{a}}$ & ${ }^{12} \mathrm{C}^{16} \mathrm{O}+{ }^{13} \mathrm{C}^{16} \mathrm{O}$ & ${ }^{12} \mathrm{C}^{18} \mathrm{O}$ & $\Delta v$ \\
\hline PdTiCO Ti-eo & $v_{\mathrm{CO}}$ & 2009.3 & 1963.9 & 45.4 & - & 1963.1 & 46.2 \\
\hline PdTiCO Pd-eo & $v_{\mathrm{CO}}$ & 1908.4 & 1866.0 & 42.4 & - & 1863.8 & 44.5 \\
\hline \multirow[t]{2}{*}{$\operatorname{PdTi}(\mathrm{CO})_{3}$} & $2 v_{\mathrm{CO}}$ asym & 3607.2 & 3528.1 & 79.1 & 3541.6 & 3519.4 & 87.8 \\
\hline & $v_{\mathrm{CO}}$ asym & 1808.9 & 1769.1 & 39.8 & $1790.0,1778.2$ & 1765.9 & 43.0 \\
\hline $\operatorname{Pd}_{\mathrm{x}} \mathrm{Ti}_{\mathrm{y}}(\mathrm{CO})_{\mathrm{z}}$ & $v_{\mathrm{CO}}$ & 1790.7 & 1750.7 & 40.0 & - & 1748.8 & 41.9 \\
\hline $\operatorname{PdTi}(\mathrm{CO})_{2}$ & $v_{\mathrm{CO}}$ asym & 1745.3 & 1706.6 & 38.7 & 1719.9 & 1704.9 & 40.4 \\
\hline $\mathrm{Pd}_{\mathrm{x}} \mathrm{Ti}_{\mathrm{y}}(\mathrm{CO})_{2}$ & $v_{\mathrm{CO}}$ asym & 1718.9 & 1680.2 & 38.6 & 1689.8 & 1679.5 & 39.4 \\
\hline
\end{tabular}

a $\Delta v$ is the difference between the ${ }^{12} \mathrm{C}^{16} \mathrm{O}$ frequency and the ${ }^{13} \mathrm{C}^{16} \mathrm{O}$ or ${ }^{12} \mathrm{C}^{18} \mathrm{O}$ frequency

${ }^{\mathrm{b}}$ Only the new bands obtained with the ${ }^{12} \mathrm{C}^{16} \mathrm{O}+{ }^{13} \mathrm{C}^{16} \mathrm{O}$ mixture are reported

A series of experiments were performed at $12 \mathrm{~K}$ using different $\mathrm{CO}$ concentrations (ranging from $0.5 \%$ to $2 \%$ ) with constant concentration of metal. At low $\mathrm{CO}$ concentration $(0.5 \%)$, we observed three absorptions in the $\mathrm{CO}$ stretching region (Figure 2a). When we increase the concentration to $1 \%$, the bands observed in Figure 1c appear. Between these two spectra, the intensity of the bands at 1908.4 and 1856.9 $\mathrm{cm}^{-1}\left(\mathrm{Pd}_{2} \mathrm{CO}\right)$ increase by factor 2 . With a $\mathrm{CO}$ concentration of $2 \%$, we observed that the intensity of the band at $1908.4 \mathrm{~cm}^{-1}$ increase by factor 2 , but the bands at 1745.3 and $1790.7 \mathrm{~cm}^{-1}$ increase at about factor 4 , the band at $1808.9 \mathrm{~cm}^{-1}$ increases by factor 8 , and the other two at $1769.1\left(\mathrm{Ti}_{2}(\mathrm{CO})_{2}\right)$ and $1718.9 \mathrm{~cm}^{-1}$ by factor 3. This suggests that the molecules which have signatures at $1808.9,1790.7,1745.3$ and $1718.9 \mathrm{~cm}^{-1}$ have a steochiometry in CO greater than the species observed at $1908.4 \mathrm{~cm}^{-1}$. Accompanying these absorptions in the C-O stretching region, a much weaker absorption in near-infrared region at $3607.2 \mathrm{~cm}^{-1}$ can be correlated to the strong band at $1808.9 \mathrm{~cm}^{-1}$, the PdTi(CO) $)_{3}$ molecule. 


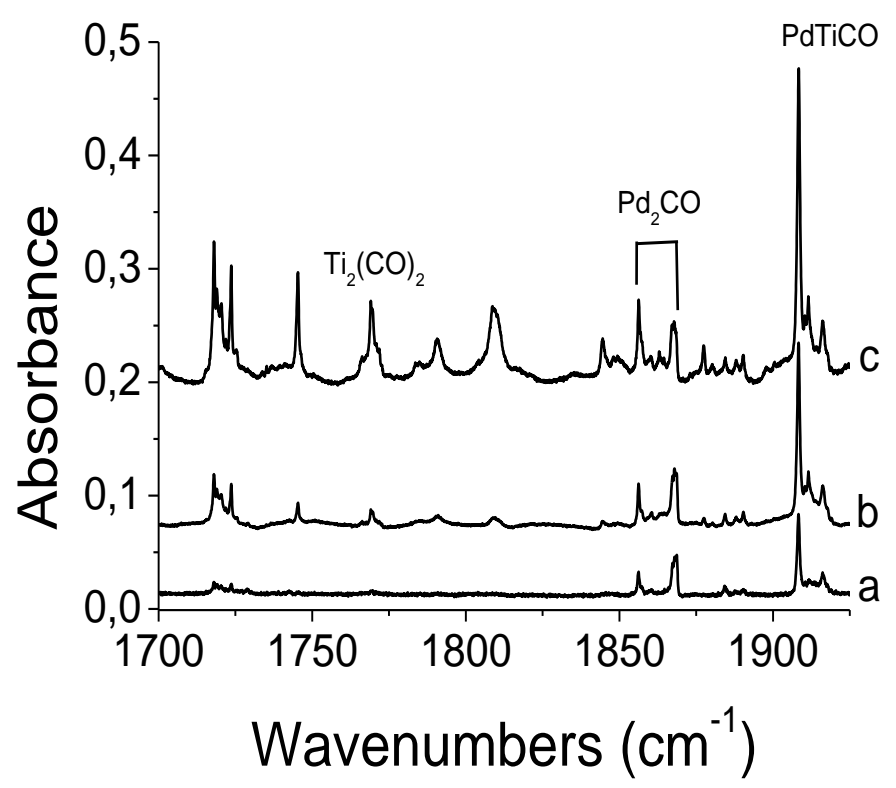

Figure 2. Infrared spectra of palladium-titanium carbonyls after deposition at $12 \mathrm{~K}$ : a $\mathrm{CO}$ concentration effect with a $\mathrm{Pd} / \mathrm{Ti} / \mathrm{Ar}$ concentration of $0.1 / 0.6 / 1000$. (a) $0.5 \%$, (b) $1 \%$, and (c) $2 \% \mathrm{CO} / \mathrm{Ar}$ mixture.

A series of experiments were performed with a constant concentration of $\mathrm{CO}$ of $2 \%$ but with different metal concentrations. When the palladium flow rate is increasing by a factor of 2 , with the same Ti rate, we observed that the intensities of the bands at 1908.4, 1808.9 and $1745.3 \mathrm{~cm}^{-1}$ are multiplied by 2 (Figure $3 \mathrm{a}$ and $3 b$ ). On the other hand, by decreasing the titanium flow rate by a factor of 2 , with the same Pd rate, we observed that the intensities of the bands at $1908.4,1808.9$ and $1745.3 \mathrm{~cm}^{-1}$ are divided by 2 (Figure $3 \mathrm{~b}$ and 3c). This suggests that these bands belong to molecules that contain one Ti atom and one Pd atom. For the bands at 1790.7 and $1718.9 \mathrm{~cm}^{-1}$, we can find other conditions (CO concentration, temperature) for which the intensity variation of these bands does not have a linear dependence with respect to the titanium or the palladium concentration. These species probably involve more than one Ti or Pd atom, but no definitive identification is possible. For this reason, these bands appear in the Table 1 with the assignment $\operatorname{Pd}_{\mathrm{x}} \operatorname{Ti}_{\mathrm{y}}$ for the metals. 


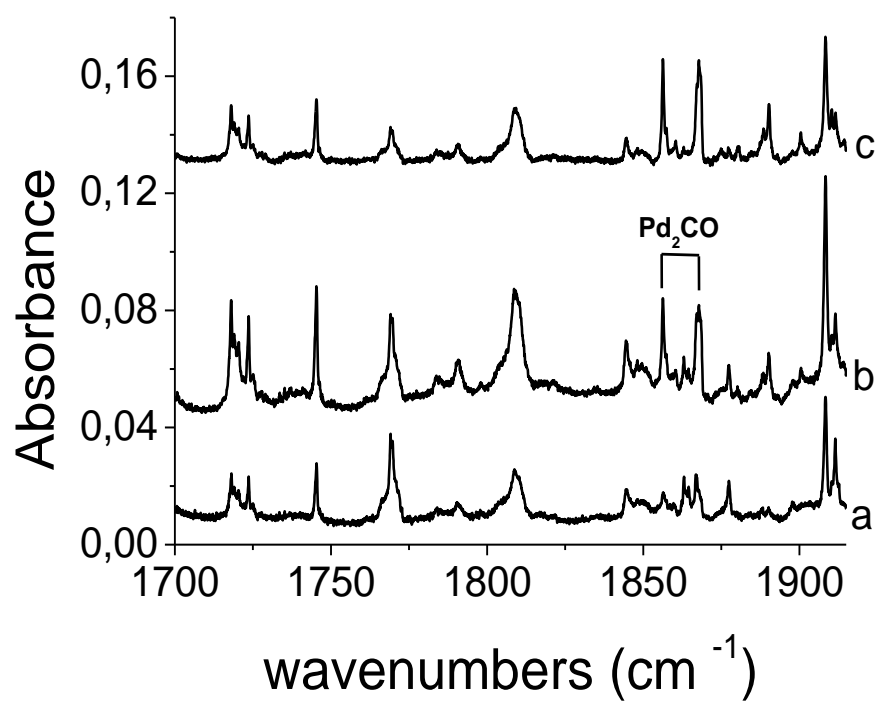

Figure 3. Infrared spectra of palladium-titanium carbonyls after deposition at $12 \mathrm{~K}$ : a metal concentration study with a $2 \% \mathrm{CO} / \mathrm{Ar}$ mixture. $\mathrm{Pd} / \mathrm{Ti} / \mathrm{Ar}$ concentration of (a) $0.2 / 0.3 / 1000$, (b) $0.4 / 0.3 / 1000$, and (c) $0.4 / 0.15 / 1000$.

Isotopic substitutions were carried out using ${ }^{13} \mathrm{C}^{16} \mathrm{O},{ }^{12} \mathrm{C}^{18} \mathrm{O}$, and a ${ }^{12} \mathrm{C}^{16} \mathrm{O}+{ }^{13} \mathrm{C}^{16} \mathrm{O}$ mixture. The results are presented in Figure 4 and Table 1. The band at $1908.4 \mathrm{~cm}^{-1}$ shifts to 1866.3 and $1863.9 \mathrm{~cm}^{-1}$ when ${ }^{12} \mathrm{C}^{16} \mathrm{O}$ is replaced by ${ }^{13} \mathrm{C}^{16} \mathrm{O}$ and ${ }^{12} \mathrm{C}^{18} \mathrm{O}$, respectively. With a ${ }^{12} \mathrm{C}^{16} \mathrm{O}+{ }^{13} \mathrm{C}^{16} \mathrm{O}$ mixture (Figure 4.A) no further bands appeared which means this molecule contains a single CO. The band at $1808.9 \mathrm{~cm}^{-1}$ shifts to 1769.1 and $1765.9 \mathrm{~cm}^{-1}$ when ${ }^{12} \mathrm{C}^{16} \mathrm{O}$ is replaced by ${ }^{13} \mathrm{C}^{16} \mathrm{O}$ and ${ }^{12} \mathrm{C}^{18} \mathrm{O}$, respectively, and with a ${ }^{12} \mathrm{C}^{16} \mathrm{O}+$ ${ }^{13} \mathrm{C}^{16} \mathrm{O}$ mixture, two further bands appear at 1790.0 and $1778.2 \mathrm{~cm}^{-1}$ (Figure 4. B). These two supplementary bands assigned the presence of three carbonyl groups in this molecule. These observations will be discussed in more details in the section devoted to the vibrational analysis. The bands at $1790.7 \mathrm{~cm}^{-1}$ shifts to 1750.7 and $1748.8 \mathrm{~cm}^{-1}$ when ${ }^{12} \mathrm{C}^{16} \mathrm{O}$ is replaced by ${ }^{13} \mathrm{C}^{16} \mathrm{O}$ and ${ }^{12} \mathrm{C}^{18} \mathrm{O}$, respectively. With the ${ }^{12} \mathrm{C}^{16} \mathrm{O}+{ }^{13} \mathrm{C}^{16} \mathrm{O}$ mixture, the corresponding spectral region is congested, essentially by $\operatorname{PdTi}(\mathrm{CO})_{3}$, and no absorption can be detected. It is not possible to conclude about the number of carbonyls in this molecule. On the other hand, the bands at 1745.3 and $1718.9 \mathrm{~cm}^{-1}$ shift to 1706.6 and $1680.2 \mathrm{~cm}^{-1}$ when ${ }^{12} \mathrm{C}^{16} \mathrm{O}$ is replaced by ${ }^{13} \mathrm{C}^{16} \mathrm{O}$ and shift to 1704.9 and $1679.5 \mathrm{~cm}^{-1}$ when ${ }^{12} \mathrm{C}^{16} \mathrm{O}$ is replaced by ${ }^{12} \mathrm{C}^{18} \mathrm{O}$, respectively. With a ${ }^{12} \mathrm{C}^{16} \mathrm{O}+{ }^{13} \mathrm{C}^{16} \mathrm{O}$ 
mixture two further bands appeared at 1719.9 and $1689.8 \mathrm{~cm}^{-1}$ (Figure 4. C), which is appropriate for the presence of two carbonyl groups in these molecules.

Irradiations at different wavelengths in the visible and near-UV were carried out. Only one in the range 450-600 nm giving rise significant effects will be described below. The Pd and Ti concentration remains high, that of $\mathrm{CO}$ in $\mathrm{Ar}$ is 2/1000. As photoconversion processes are noticeably dependent on the initial state, the results reported below describe irradiation performed just after deposition. The Figure 5 shows an example of a conversion for a long time of the band at $2009.3 \mathrm{~cm}^{-1}$, relatively weak before irradiation, which increases significantly, and the band at $1908.4 \mathrm{~cm}^{-1}$ that decreases after irradiation. The Figure 6 displays the time development of the $v_{\mathrm{CO}}$ band intensities normalized to their values before irradiation for the two PdTiCO Pd-eo and PdTiCO Ti-eo species. After $15 \mathrm{~min}$ of irradiation the band at $1908.4 \mathrm{~cm}^{-1}$ decreases by $63 \%$ from its initial value, the one at $2009.3 \mathrm{~cm}^{-1}$ increases by a factor of 2 . Defining the conversion advancement as $a_{t}=\left(I_{t}-I_{0}\right) /\left(I_{\infty}-I_{0}\right)$, where I means the intensity of the CO stretching band and 0 , $t$, and oo refer to the initial, intermediate and final times, we deduce from Figure 6 that $a_{t}$ has the same value for the two bands whatever $t$. As a corollary the characteristic time of conversion $t_{1 / 2}$, defined as the time required for converting half of the quantity converted at infinite time (here reduced to $15 \mathrm{~min}$ ), is found equal to $3.5 \mathrm{~min}$ for the two species. 


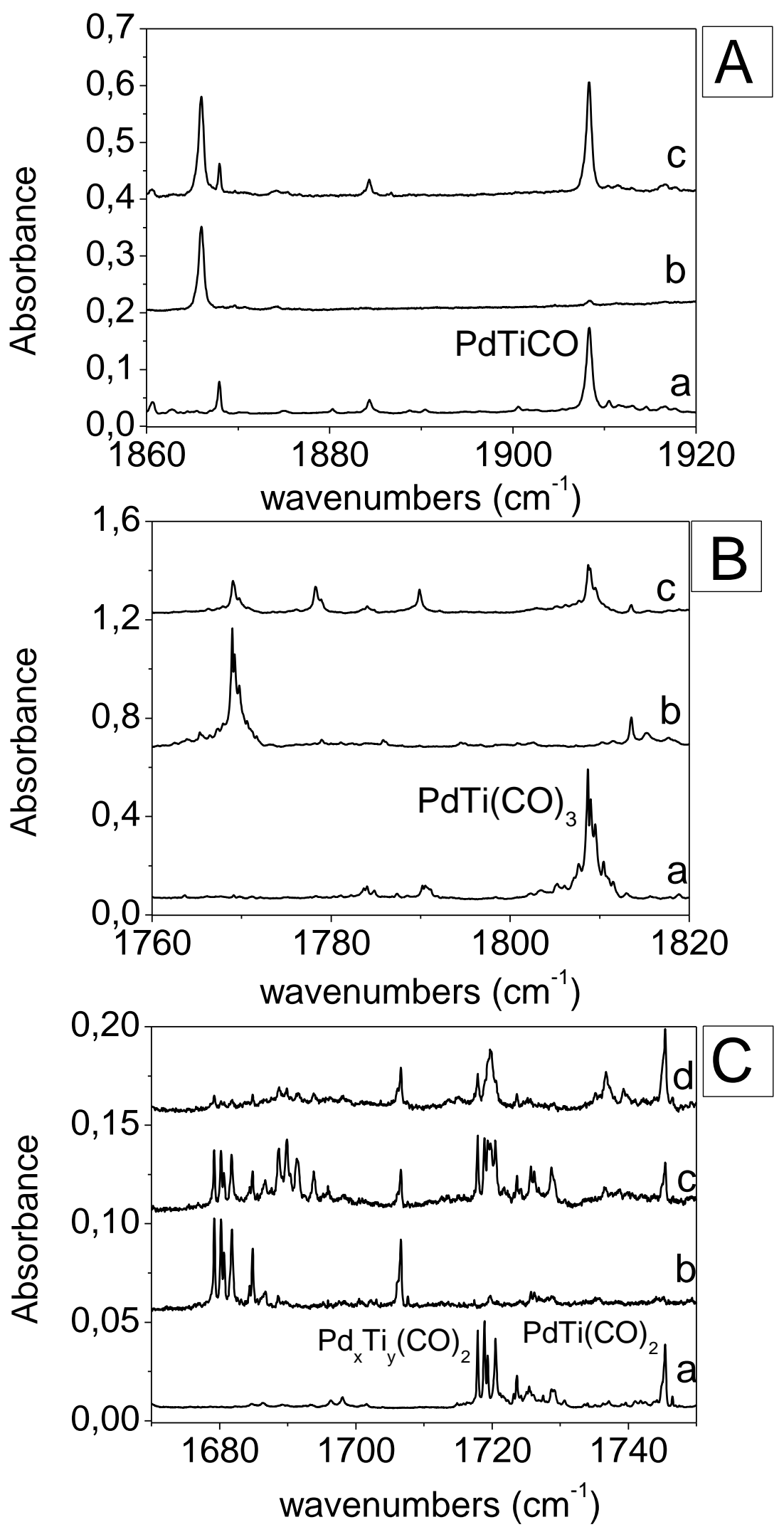

Figure 4. Infrared spectra for $\operatorname{PdTiCO}(\mathrm{A}), \operatorname{PdTi}(\mathrm{CO})_{3}(\mathrm{~B}), \operatorname{PdTi}(\mathrm{CO})_{2}$ and $\mathrm{Pd}_{\mathrm{x}} \mathrm{Ti}_{\mathrm{y}}(\mathrm{CO})_{2}(\mathrm{C})$ with a $\mathrm{Pd} / \mathrm{Ti} / \mathrm{Ar}$ concentration of $0.1 / 0.6 / 1000$ at $20 \mathrm{~K}$. (a) ${ }^{12} \mathrm{C}^{16} \mathrm{O}$, (b) ${ }^{13} \mathrm{C}^{16} \mathrm{O}$ and (c) ${ }^{12} \mathrm{C}^{16} \mathrm{O}+{ }^{13} \mathrm{C}^{16} \mathrm{O}$. In $\mathrm{C}$, (c) corresponds to a spectrum with $\mathrm{CO} / \mathrm{Ar}=0.2 \%$ and $(\mathrm{d})$ with $\mathrm{CO} / \mathrm{Ar}=0.5 \%$. 


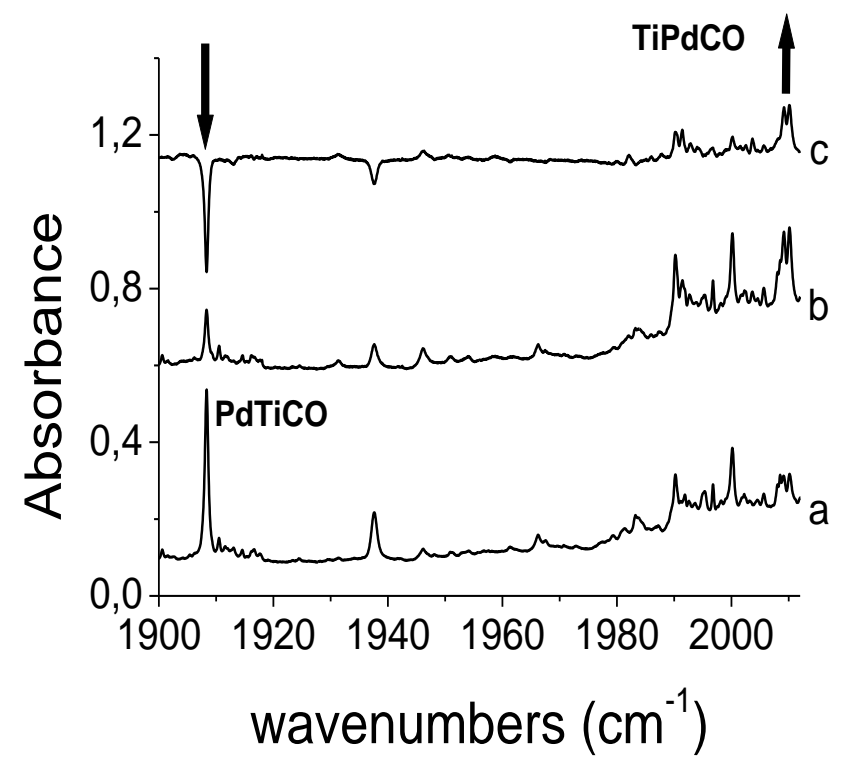

Figure 5. Infrared spectra in the $1900-2012 \mathrm{~cm}^{-1}$ region for a $\mathrm{Pd} / \mathrm{Ti} / \mathrm{CO} / \mathrm{Ar}=0.3 / 0.3 / 2 / 1000$ sample deposited at $20 \mathrm{~K}$ for $90 \mathrm{~min}$. Displayed spectra are recorded at $12 \mathrm{~K}$ (a) before irradiation, (b) after $15 \mathrm{~min}$ irradiation in the visible $(\lambda=[450,600] \mathrm{nm})$, and (c) difference between spectrum (a) and (b).

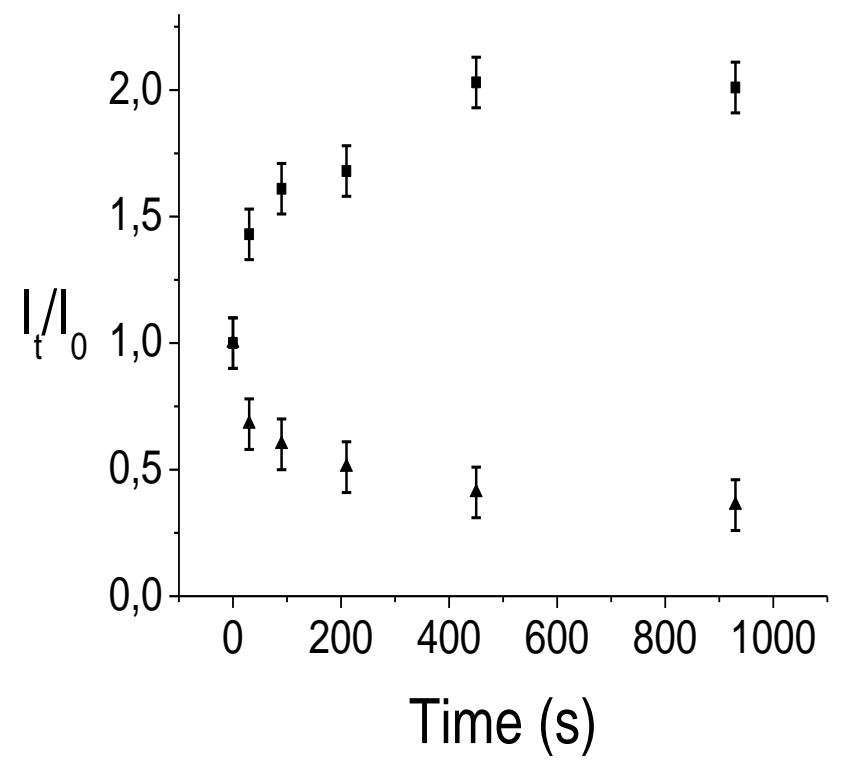

Figure 6. Time development of the areas of the bands of PdTiCO Pd-eo ( $\mathbf{\Delta})$ at $1908.4 \mathrm{~cm}^{-1}$ and of PdTiCO Ti-eo (匹) at $2009.3 \mathrm{~cm}^{-1}$ versus the irradiation duration at $\lambda=[450,600] \mathrm{nm}$. 


\section{THEORETICAL CALCULATIONS}

\section{Structural and energetic analyses}

Quantum chemical calculations have been performed to determine the molecular structures and to support the vibrational frequency analysis of the studied metal-carbonyl clusters. Overall, we calculated three structures for the $\operatorname{PdTi}(\mathrm{CO})$ monocarbonyl, 6 structures for the $\operatorname{PdTi}(\mathrm{CO})_{2}$ dicarbonyl and one structure for the $\operatorname{PdTi}(\mathrm{CO})_{3}$ tricarbonyl compounds. All the cartesian optimized coordinates are reported in the Supporting Information.

Three bonding modes for PdTi(CO) have been investigated: bent Pd-end-on (Pd-eo), bent Ti-end-on (Ti-eo) and $\mu$-bridge $(\mu$-br). These three structures are connected to each other by two transition states (Figure 7). Three minima are labeled as to S1 (bent Ti-end-on), S2 ( $\mu$-bridge) and S3 (Pd-end-on). The binding energies reported on Figure 7 are calculated with respect to free $\mathrm{CO}\left({ }^{1} \Sigma, \mathrm{r}_{\mathrm{CO}}=1.126 \AA\right.$ ), and the $\operatorname{PdTi}\left({ }^{3} \Sigma, \mathrm{r}_{\mathrm{PdTi}}=2.197 \AA\right)$ molecules including the zero-point-energy. On the ground of the energetic results, two bent end-on structures $(\mathrm{S} 1$ and $\mathrm{S} 3)$ are isoenergetic $\left(\mathrm{D}_{0}=-24.7 \mathrm{kcal} / \mathrm{mol}\right)$, but the $\mu$-bridge structure (S2) is slightly less stable than two bent structures by about of $5 \mathrm{kcal} / \mathrm{mol}$. We should note that the three structures of $\operatorname{PdTi}(\mathrm{CO})$ optimized at the singlet state were found significantly above the triplet states (see the Supporting Information). Two transition states (TS12 and TS23) were found which connect S1 to S2, and S2 to $\mathrm{S} 3$, respectively. We note that the $\mathrm{S} 2$ conversion to $\mathrm{S} 1$ structure occurs by overcoming a small energetic barrier (less than $1 \mathrm{kcal} / \mathrm{mol}$ ), while the barrier height between S2 and S3 is calculated to be large enough $(\approx$ $12 \mathrm{kcal} / \mathrm{mol}$ ) to prevent any thermal conversion at low temperature. Consequently, the triplet S1 and S3 structures corresponding to the global minima are actually candidates to be experimentally observed in cold rare gas matrix. 


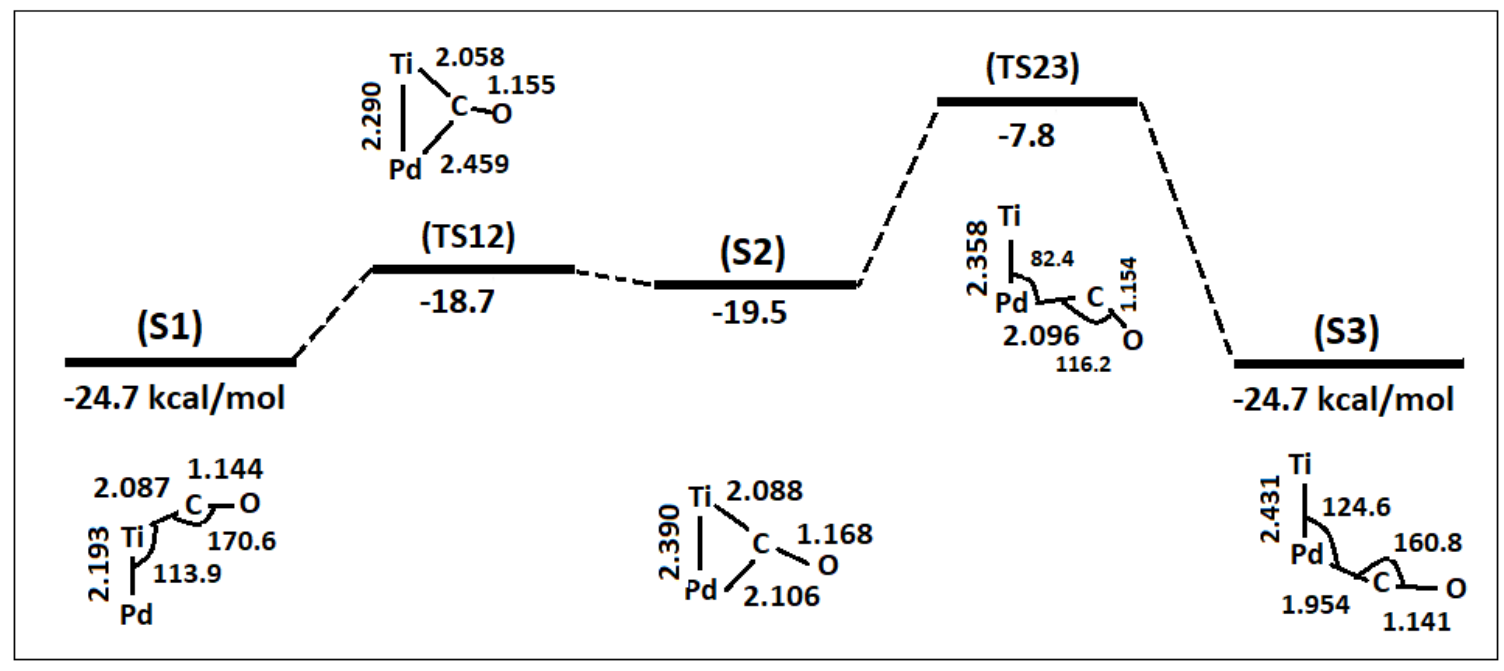

Figure 7. Stationary points on the triplet spin state surface obtained for the PdTi-monocarbonyl compounds.

Distances are in $\AA$ and angles in degrees.

For the PdTi-polycarbonyl compounds, we optimized six structures for $\operatorname{PdTi}(\mathrm{CO})_{2}$ and one structure belonging to the $C_{3 v}$ group for $\operatorname{PdTi}(\mathrm{CO})_{3}$. The singlet structure in the latter case is calculated to be above the triplet one by $3.8 \mathrm{kcal} / \mathrm{mol}$. The $\mathrm{PdTi}(\mathrm{CO})_{2}$ and $\mathrm{PdTi}(\mathrm{CO})_{3}$ compounds are predicted to have spin triplet ground states with $\mathrm{C}_{2 \mathrm{v}}$ and $\mathrm{C}_{3 \mathrm{v}}$ symmetry, respectively (Figure 8). All the optimized structures are reported in the Supporting Information. Binding energy corrected for the zero-point energy has been calculated to be -21.2 and $-32.0 \mathrm{kcal} / \mathrm{mol}$ for $\operatorname{PdTi}(\mathrm{CO})_{2}$ and $\operatorname{PdTi}(\mathrm{CO})_{3}$ with respect to $\mathrm{E}(\mathrm{PdTiCO} \mathrm{Ti}-\mathrm{eo})+\mathrm{E}(\mathrm{CO})$ and $\mathrm{E}(\mathrm{PdTi}(\mathrm{CO}) 2)+\mathrm{E}(\mathrm{CO})$. The energy gain relative to the addition of a third carbonyl is most important than that for the first and second one. However, it must be remembered that this energy shift reflects the global geometrical variation in the structure of the studied compounds. For instance, the C-O bond length (just like to Ti-C distance) increases as PdTiCO Pd-eo $<$ PdTiCO Ti-eo $<\mathrm{PdTi}(\mathrm{CO})_{3}<\mathrm{PdTi}(\mathrm{CO})_{2}$, while the Ti-Pd distance varies as PdTiCO Ti-eo $<$ PdTiCO Pd-eo $<\operatorname{PdTi}(\mathrm{CO})_{2}<\operatorname{PdTi}(\mathrm{CO})_{3}$. 


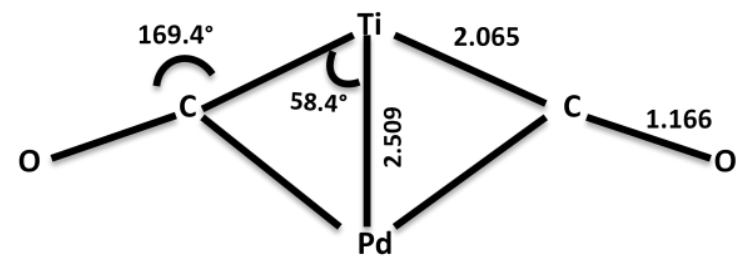

${ }^{3} B_{2}\left(C_{2 v}\right)$

$\mathrm{D}_{0}=-20.2 \mathrm{Kcal} / \mathrm{mol}$

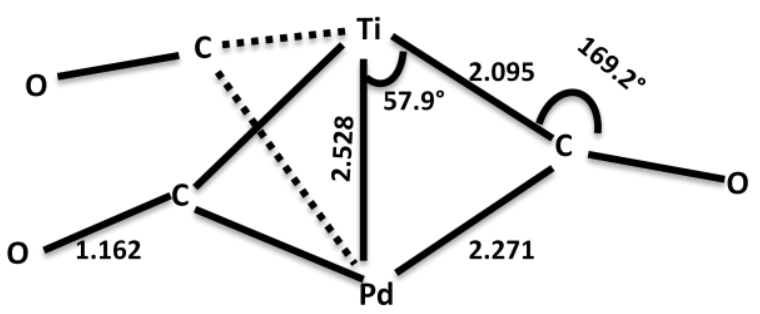

${ }^{3} \mathrm{~A}_{1} \quad\left(\mathrm{C}_{3 \mathrm{v}}\right)$

$\mathrm{D}_{0}=-32.0 \mathrm{Kcal} / \mathrm{mol}$

Figure 8. Optimized geometrical parameters (distance in $\AA$ and angle in degrees) and ZPE corrected binding energy (in $\mathrm{kcal} / \mathrm{mol}$ ) for the ground state of the $\operatorname{PdTi}(\mathrm{CO})_{2}$ and $\operatorname{PdTi}(\mathrm{CO})_{3}$ compounds.

\section{Nature of chemical bonding}

According to the QTAIM, the positive values of the Laplacian at the bond critical point (BCP) are associated with closed-shell interactions, whereas, $\nabla^{2} \rho<0$, indicates shared interactions (covalent bonds). In addition, the sign and magnitude of the total electronic energy density at the BCP, $\mathrm{H}(\mathrm{r})$, is usually used as another criterion to evaluate the importance of sharing of electrons (when $\mathrm{H}(\mathrm{r})<0$ ). In Table 2 are gathered the topological descriptors of bonding in the compounds studied in this work. One can easily note existence of a bond path for $\mathrm{C}-\mathrm{O}, \mathrm{Pd}-\mathrm{C}, \mathrm{Ti}-\mathrm{C}$ and $\mathrm{Ti}-\mathrm{Pd}$ pairs of atoms. The Laplacian of the electron density is always positive indicating a closed-shell interaction between these bonded atoms with partially covalent character $(\mathrm{H}(\mathrm{r})<0)$.

The electron density at the $\mathrm{C}-\mathrm{O} \mathrm{BCP}$ ranges from $0.454 \mathrm{e} / \mathrm{a}_{0}{ }^{3}$ in the $\mathrm{PdTi}(\mathrm{CO})_{2}$ to $0.505 \mathrm{e} / \mathrm{a}_{0}{ }^{3}$ in free CO. The negative value of the energy density at the $\mathrm{C}-\mathrm{O} \mathrm{BCP}(\approx-0.88)$ evidences the polar covalent character of the $\mathrm{C}-\mathrm{O}$ chemical bonding. The electron density being a local property, its change from one compound to another could be used actually as a measure of the variation of a local spectroscopic property such as force constant for example. Consequently, we expect that the $\mathrm{C}-\mathrm{O}$ vibrational frequency varies in the same ordering as the electron density at the $\mathrm{C}-\mathrm{O}$ bond critical point: free $\mathrm{CO}>\mathrm{PdTiCO} \mathrm{Pd}-\mathrm{eo}>\mathrm{PdTiCO} \mathrm{Ti}-$ eo $>\operatorname{PdTi}(\mathrm{CO})_{3}>\operatorname{PdTi}(\mathrm{CO})_{2}$. That means that the greatest red-shift of the $\mathrm{C}-\mathrm{O}$ vibrational frequency is expected to be observed for the $\operatorname{PdTi}(\mathrm{CO})_{2}$ compound. Furthermore, the variation of the electron density at 
the $\mathrm{C}-\mathrm{O} \mathrm{BCP}$ well correlates with the variation of the $\mathrm{C}-\mathrm{O}$ bond length with a correlation coefficient close to one $\left(\mathrm{R}^{2} \approx 0.998\right)$.

A multivariate simultaneous analysis of the variation of two parameters - namely distance and electron density at BCP - for each chemical bonds evolved in compounds, allows us not only to understand the variation of the force constant but also to highlight the distribution of vibrational energy within various bonds. To illustrate such an analysis, we compare the two monocarbonyl species, PdTiCO Pd-eo and PdTiCO Ti-eo In going from Pd-eo to Ti-eo, we note that the Pd-Ti distance decreases while the C-O bond length increases slightly. This is consistent with the change in the electron density on the Pd-Ti and C-O bond critical points. It is therefore expected that the Pd-Ti vibrational frequency is higher in PdTiCO Ti-eo than in PdTiCO Pd-eo. In a similar way, the C-O vibrational frequency is found to be greater in PdTiCO Pdeo than in PdTiCO Ti-eo (see Figure S1). These opposite trends - for both interatomic distances and vibrational frequencies - make these two species remain substantially isoenergetic.

One can easily note that the presence of a BCP between two metal centers in all the studied compounds, even though its electron density slightly decreases when adding a carbonyl ligand. The bonding between $\mathrm{C}$ atom and metal center decreases in going from monoligand to triligand compounds leading to a quasi-identical electron density at $\mathrm{Pd}-\mathrm{C}$ and $\mathrm{Ti}-\mathrm{C}$ BCPs in the triple $\mu$-bridge $\mathrm{PdTi}(\mathrm{CO})_{3}$ species $(\approx-$ $\left.0.076 \mathrm{e} / \mathrm{a}_{0}^{3}\right)$

\begin{tabular}{|l|l|l|}
\hline Compounds & $B C P\left(r_{c}\right)$ & $\rho\left(r_{c}\right), \nabla^{2} \rho\left(r_{c}\right), H\left(r_{c}\right)$ \\
\hline $\mathrm{CO}$ & $\mathrm{C}-\mathrm{O}$ & $0.505,0.459,-0.941$ \\
\hline TiPd & $\mathrm{Pd}-\mathrm{Ti}$ & $0.103,0.330,-0.035$ \\
\hline \multirow{2}{*}{$\begin{array}{l}\text { PdTi(CO) } \\
\text { Bent Pd end-on }\end{array}$} & $\mathrm{C}-\mathrm{O}$ & $0.487,0.350,-0.899$ \\
\cline { 2 - 3 } & $\mathrm{Pd}-\mathrm{C}$ & $0.135,0.398,-0.057$ \\
\cline { 2 - 3 } & $\mathrm{Pd}-\mathrm{Ti}$ & $0.062,0.176,-0.015$ \\
\hline \multirow{2}{*}{$\begin{array}{l}\text { PdTi(CO) } \\
\text { Bent Ti end-on }\end{array}$} & $\mathrm{C}-\mathrm{O}$ & $0.482,0.344,-0.886$ \\
\cline { 2 - 3 } & $\mathrm{Ti}-\mathrm{C}$ & $0.081,0.321,-0.015$ \\
\cline { 2 - 3 } & $\mathrm{Pd}-\mathrm{Ti}$ & $0.107,0.334,-0.038$ \\
\hline PdTi(CO) 2 & $\mathrm{C}-\mathrm{O}$ & $0.454,0.108,-0.821$ \\
\hline
\end{tabular}




\begin{tabular}{|l|l|l|}
\hline Double $\mu$-bridge & $\mathrm{Pd}-\mathrm{C}$ & $0.106,0.179,-0.037$ \\
\cline { 2 - 3 } & $\mathrm{Ti}-\mathrm{C}$ & $0.081,0.189,-0.020$ \\
\cline { 2 - 3 } & $\mathrm{Pd}-\mathrm{Ti}$ & $0.043,0.109,-0.007$ \\
\hline \multirow{3}{*}{$\begin{array}{l}\text { PdTi }(\mathrm{CO})_{3} \\
\text { Triple } \mu \text {-bridge }\end{array}$} & $\mathrm{C}-\mathrm{O}$ & $0.463,0.140,-0.842$ \\
\cline { 2 - 3 } & $\mathrm{Pd}-\mathrm{C}$ & $0.076,0.137,-0.019$ \\
\cline { 2 - 3 } & $\mathrm{Ti}-\mathrm{C}$ & $0.079,0.289,-0.015$ \\
\cline { 2 - 3 } & $\mathrm{Pd}-\mathrm{Ti}$ & $0.056,0.122,-0.013$ \\
\hline
\end{tabular}

Table 2. Some local topological properties on the bonded atoms in the studied compounds. All parameters are given in atomic units.

All the observed structures have a triplet spin state. The QTAIM analysis indicates that both alpha electrons are almost localized on the $\mathrm{Ti}$ atom. The addition of three carbonyls to the heterodimer could not pairing two single electrons to give a singlet ground state. In contrast, interaction between one carbonyl ligand with the palladium dimer (triplet ground state) leads to a $\mu$-bridged compound at the singlet state. The localization of one alpha electron per $\mathrm{Pd}$ atom makes the spin pairing in the $\mathrm{Pd}_{2}(\mathrm{CO})$ easy to achieve. ${ }^{23}$

\section{Vibrational analysis and comparison with calculations}

All the experimentally observed vibrational frequencies for various isotopic substitutions as well as the corresponding DFT calculated harmonic wavenumbers are reported in Table 3. However, a complete listing of all the calculated frequencies for all the studied compounds is provided in the Supporting information.

In our experiments, no band has been detected in the far infrared region. It is in line with our theoretical data that infrared intensities are very small in the far infrared region (see Supporting information). Accounting for the detectivity of the argon matrix setup, only modes with intensities larger than $35 \mathrm{~km} / \mathrm{mol}$ are likely to be observed. Over all the calculated frequencies for PdTiCO (Pd-eo), PdTiCO (Ti-eo), PdTi(CO) $)_{2}$, and PdTi $(\mathrm{CO})_{3}$, only two vibrational frequencies have been calculated to have an IR Intensity greater than $35 \mathrm{~km} / \mathrm{mol}$ : a band located at $270 \mathrm{~cm}^{-1}$ band (in-plane Pd-C-O bending) for PdTiCO 
(Pd-eo) and another one at $378 \mathrm{~cm}^{-1}$ (in-phase out-of-plane Pd-C-O bending) for PdTi(CO) $)_{2}$ for which the IR intensities are 47 and $49 \mathrm{~km} / \mathrm{mol}$ respectively. This spectral region $\left(200-400 \mathrm{~cm}^{-1}\right)$ is congested by strong absorptions at 310 and $263 \mathrm{~cm}^{-1}$ which belonged to $\mathrm{Pd}(\mathrm{CO})_{4}$ and $\mathrm{Pd}(\mathrm{CO})_{2},{ }^{10}$ respectively.

Table 3. Comparison of the experimental frequencies with the theoretical harmonic vibrational data (in $\mathrm{cm}^{-1}$ ) of the observed molecules with the isotopic shifts.

\begin{tabular}{|c|c|c|c|c|c|c|c|}
\hline molecules & assignment & & ${ }^{12} \mathrm{C}^{16} \mathrm{O}$ & ${ }^{13} \mathrm{C}^{16} \mathrm{O}$ & $\Delta v$ & ${ }^{12} \mathrm{C}^{18} \mathrm{O}$ & $\Delta v$ \\
\hline \multirow{2}{*}{$\begin{array}{l}\text { PdTiCO } \\
\text { Pd-eo }\end{array}$} & $v_{\mathrm{CO}}$ & Exp & 2009.3 & 1963.9 & 45.4 & 1963.1 & 46.2 \\
\hline & & DFT & 2083 & 2035 & 48 & 2033 & 50 \\
\hline \multirow{2}{*}{$\begin{array}{l}\text { PdTiCO } \\
\text { Ti-eo }\end{array}$} & $v_{\mathrm{CO}}$ & Exp & 1908.4 & 1866.0 & 42.4 & 1863.8 & 44.5 \\
\hline & & DFT & 2027 & 1982 & 45 & 1978 & 49 \\
\hline \multirow[t]{2}{*}{$\operatorname{PdTi}(\mathrm{CO})_{3}$} & $v_{\mathrm{CO}}$ asym & Exp & 1808.9 & 1769.1 & 39.8 & 1765.9 & 43.0 \\
\hline & & DFT & 1907 & 1864 & 43 & 1861 & 46 \\
\hline \multirow[t]{2}{*}{$\operatorname{PdTi}(\mathrm{CO})_{2}$} & $v_{\mathrm{CO}}$ asym & Exp & 1745.3 & 1706.6 & 38.7 & 1704.9 & 40.4 \\
\hline & & DFT & 1885 & 1843 & 42 & 1840 & 45 \\
\hline
\end{tabular}

${ }^{\text {a }}$ Only the new bands obtained with the ${ }^{12} \mathrm{C}^{16} \mathrm{O}+{ }^{13} \mathrm{C}^{16} \mathrm{O}$ mixture are reported

As discussed above, four main observed bands, located at 2009.3, 1908.4, 1745.3, and $1808.9 \mathrm{~cm}^{-1}$, have been assigned to PdTiCO Pd-eo, PdTiCO Ti-eo, $\operatorname{PdTi}(\mathrm{CO})_{2}$, and $\mathrm{PdTi}(\mathrm{CO})_{3}$, respectively, on the basis of concentration effects, isotopic substitution and DFT theoretical predictions. Compared to the free CO complex, the calculated red-shifts are 128, 184, 326, and $400 \mathrm{~cm}^{-1}$ for the PdTiCO Pd-eo, PdTiCO Ti-eo, $\operatorname{PdTi}(\mathrm{CO})_{3}$, and $\operatorname{PdTi}(\mathrm{CO})_{2}$ molecules, respectively, which are close to the experimental ones, 129, 230, 329, and $393 \mathrm{~cm}^{-1}$. Furthermore, the calculated frequency shifts due to the ${ }^{12} \mathrm{C} /{ }^{13} \mathrm{C}$ and ${ }^{16} \mathrm{O} /{ }^{18} \mathrm{O}$ isotopic substitutions agree well with the experimental values and give strong support for the assignation of these bands.

For the PdTi(CO) $)_{3}$ molecule, we also observe a weak band at $3607.2 \mathrm{~cm}^{-1}$. The assignment of this band to an overtone can be derived from the position and isotopic shift of the observed fundamental. The $3607.2 \mathrm{~cm}^{-1}$ band has a ${ }^{12} \mathrm{CO} /{ }^{13} \mathrm{CO}$ frequency shift of $79.1 \mathrm{~cm}^{-1}$, almost twice $\left(39.8 \mathrm{~cm}^{-1}\right)$ the one obtained for the frequency at $1808.9 \mathrm{~cm}^{-1}$. We can thus deduce the anharmonicity of the $\mathrm{C}-\mathrm{O}$ stretching vibrational 
frequency $\left(5.4 \mathrm{~cm}^{-1}\right)$ which is similar to the typical value for an asymmetric stretching overtone of a transition metal tricarbonyl ${ }^{41}$. For these reasons, we attributed the $3607.2 \mathrm{~cm}^{-1}$ band to the asym $2 v_{\mathrm{CO}}$ of $\operatorname{PdTi}(\mathrm{CO})_{3}$.

As shown in the experimental results, the PdTi heterodimer reacts spontaneously with CO to form two PdTi-carbonyl coumpounds: PdTiCO and TiPdCO. Visible irradiation in the 450-600 nm range provides sufficient energy for the PdTiCO Ti-eo molecule to overcome the reaction barrier to give the PdTiCO Pd-eo molecule (Fig. 7). The confirmation of this interconversion is obtained through the kinetic study. Our PFT ealculations revealed that this isemerization reaction was $17 \mathrm{kcal} / \mathrm{mol}$, Our DFT calculations show that the energy barrier between PdTiCO and TiPdCO is $17 \mathrm{kcal} / \mathrm{mol}$, and the relative energy values of these two molecules are the same $(-24.7 \mathrm{kcal} / \mathrm{mol})$, and the intensities of the CO stretching vibration are close (1254 and $1100 \mathrm{~km} / \mathrm{mol}$ for PdTiCO Ti-eo and PdTiCO Pd-eo, respectively, Supporting Information). With the same relative energy, the PdTiCO Ti-eo and PdTiCO Pd-eo molecules must be formed in the same amounts in the sample, but the experimental result is different than calculated one since the experimental $\mathrm{CO}$ intensity for PdTiCO Ti-eo is 2.5 times higher than for PdTiCO Pd-eo, and the calculated ratio is 1.14 (1254/1100). This experimental observation can be explained by the absence of bridged structure (PdTiCO $\mu$-bridge) in our experiment. Indeed, the energy barrier between transition state (TS12) and the PdTiCO $\mu$ bridge structure is nearly negligible $(1 \mathrm{kcal} / \mathrm{mol})$ it seems that this barrier is not high enough to allow this structure to be stabilized in the Ar matrix, which turns into PdTiCO Ti-eo (Figure 7). We can assume that in the entrance of reaction, the PdTiCO Ti-eo, PdTiCO Pd-eo and PdTiCO $\mu$-bridge molecules are formed in a same amount, and since all the PdTiCO $\mu$-bridge molecules turn into PdTiCO Ti-eo molecules, the theoretical intensity ratio between PdTiCO Ti-eo and PdTiCO Pd-eo should be $2 \times 1.14=2.3$, in agreement with the experimental one.

Using laser ablation technique for producing Ti atoms, Andrews et al. observed TiCO molecule in excess $\operatorname{argon}^{25}$, but by thermal evaporation technique, TiCO is not observed ${ }^{26}$, and our results on the Ti + $\mathrm{CO}$ reaction are in agreement with this late observation. In this case it is impossible to form $\mathrm{S} 1$ from the reaction TiCO + Pd. PdTiCO Ti-eo, PdTiCO $\mu$-bridge, and PdTiCO Pd-eo can be only formed from 
diatomic $\mathrm{Pd}-\mathrm{Ti}$ with $\mathrm{CO}$ molecule in the excess argon matrix. In fact, with a sample at low $\mathrm{CO} / \mathrm{Ar}$ concentration, 1/1000, we observe the formation of a small amount of PdTiCO Ti-eo and PdTiCO Pd-eo at $12 \mathrm{~K}$. Annealing the sample at 20,26 and $30 \mathrm{~K}$ after deposition allows the Ti and Pd atoms to diffuse in the matrix. After each annealing we observed the growth of the $\mathrm{CO}$ bands for the two isomers. This observation means that PdTi reacts with $\mathrm{CO}$ in the ground state.

Since $\mathrm{Pd}_{2} \mathrm{CO}$ end-on and $\mathrm{PdTiCO} \mathrm{Pd}$-eo have a similar structure, we can compare these two molecules. Indeed, the $\mathrm{Pd}-\mathrm{C}-\mathrm{O}$ and $\mathrm{M}-\mathrm{Pd}-\mathrm{C}(\mathrm{M}=\mathrm{Ti}$ or $\mathrm{Pd})$ angles, the $\mathrm{C}-\mathrm{O}$ length, and the $\mathrm{CO}$ frequency are similar for both molecules: $169^{\circ}$ versus $161^{\circ}, 116^{\circ}$ versus $125^{\circ}, 1.15$ versus $1.14 \AA$, 2015 versus $2009 \mathrm{~cm}^{-1}$, for $\mathrm{Pd}_{2} \mathrm{CO}$ versus $\mathrm{PdTiCO} \mathrm{Pd}-\mathrm{eo}$, respectively. However, the $\mathrm{Pd}-\mathrm{C}$ bond length makes the distinction between these two molecules: it changes from $1.87 \AA$ in $\mathrm{Pd}_{2} \mathrm{CO}$ to $1.95 \AA$ in PdTiCO Pd-eo. This lengthening implies a weakening of the Pd-C bond.

\section{CONCLUSION}

The study of the $\mathrm{Pd}+\mathrm{Ti}+\mathrm{CO}$ reaction was performed by coupling matrix isolation FTIR spectroscopy and DFT calculations. New infrared absorption data have been observed for $\operatorname{PdTi}(C O)_{n}(n=1-3)$ molecules. The intense bands of the CO stretching appear in $2010-1700 \mathrm{~cm}^{-1}$ range and another absorption is observed in the near-infrared around $3600 \mathrm{~cm}^{-1}$ for $\operatorname{PdTi}(\mathrm{CO})_{3}$. Our technique of sublimation of Ti and Pd atoms from two filaments heated separately allowed the formation of molecules from the ground state reagents. The experimental data obtained in argon, with the help of isotopic effects, are fully supported by theoretical calculations. The most relevant structural and energetic data for the lowest lying structures have been calculated for the PdTi(CO) $(n=1-3)$, studied molecules. Selective irradiation in the 450-600 nm range leads to conversion between two isomers distinguished by the stretching frequency of the diatomic CO: PdTiCO Ti-eo $\left(v_{\mathrm{CO}}=1908.4 \mathrm{~cm}^{-1}\right)$ and PdTiCO Pd-eo $\left(v_{\mathrm{CO}}=2009.3 \mathrm{~cm}^{-1}\right)$. Finally, unlike to the singlet bridged $\mathrm{Pd}_{2} \mathrm{CO}$ the Ti atom carrying two single $\alpha$-electron is bonded to the $\mathrm{Pd}$ atom via a bond critical point within the $\operatorname{PdTi}(\mathrm{CO})_{1-3}$ molecules. 


\section{Supporting Information}

Correlation between electron density at BCPs (in a.u.) and CO and PdTi frequencies (in $\mathrm{cm}^{-1}$ ) from the calculated molecules. (Figure S1); The cartesian coordinates and the harmonic B3LYP frequencies $\left(\mathrm{cm}^{-1}\right)$ and intensities $(\mathrm{km} / \mathrm{mol})$ for the $\operatorname{PdTi}(\mathrm{CO})_{\mathrm{n}}(\mathrm{n}=1-3)$ molecules are reported for all the studied structures. (PDF)

TOC Graphic

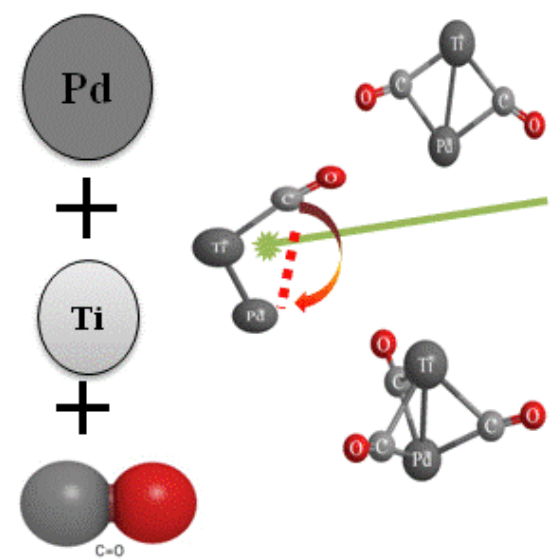

References

(1) Yao, Y.; Goodman, D. W. In situ IR spectroscopic studies of Ni surface segregation induced by CO adsorption on $\mathrm{Cu}-\mathrm{Ni} / \mathrm{SiO} 2$ bimetallic catalysts. Chem. Phys. Phys. Chem. 2014, 16, 3823-3829.

(2) Rodriguez, J. A.; Goodman, D. W. The nature of the metal-metal bond in bimetallic surfaces. Science, 1992, 257, 897-903.

(3) Gao, F.; Goodman, D. W. Pd-Au bimetallic catalysts: understanding alloy effects from planar models and (supported) nanoparticles . Chem. Soc. Rev. 2012, 41, 8009-8020.

(4) Wei, Z.; Sun, J.; Datye, A. K.; Wang, Y. Bimetallic catalysts for hydrogen generation. Chem. Soc. Rev., 2012, 41, 7994-8008. 
(5) Zhou, M. ; Andrews, L.; Bauschlicher, C. W. Spectroscopic and Theoretical Investigations of Vibrational Frequencies in Binary Unsaturated Transition-Metal Carbonyl Cations, Neutrals, and Anions. Chem. Rev. 2001,101, 1931-1961.

(6) Himmel, H. J.; Downs, A. J.; Greene, T. M. Reactions of Ground State and Electronically Excited Atoms of Main Group Elements: a Matrix Perspective. Chem. Rev. 2002, 102, 4191-4242.

(7) Chertihin, G. V.; Andrews, L. Infrared Spectra of the Reaction Products of Laser-Ablated Titanium Atoms and Oxides with Carbon Monoxide in Solid Argon. J. Am. Chem. Soc. 1995, 117, 1595-1602.

(8) Zhou, M.; Andrews, L. Infrared Spectra and Density Functional Calculations of Small Vanadium and Titanium Carbonyl Molecules and Anions in Solid Neon, J. Phys. Chem. A 1999, 103, 5259-5268.

(9) Liang, B.; Zhou, M.; Andrews, L. Reactions of Laser-Ablated Ni, Pd, and Pt Atoms with Carbon Monoxide: Matrix Infrared Spectra and Density Functional Calculations on $\mathrm{M}(\mathrm{CO})_{\mathrm{n}}(\mathrm{n}=1-4)$, $\mathrm{M}(\mathrm{CO})_{\mathrm{n}}{ }^{-}(\mathrm{n}=1-3)$, and $\mathrm{M}(\mathrm{CO})_{\mathrm{n}}{ }^{+}(\mathrm{n}=1-2),(\mathrm{M}=\mathrm{Ni}, \mathrm{Pd}, \mathrm{Pt})$. J. Phys. Chem. A. 2000, 104, 3905-3914.

(10) Tremblay, B.; Manceron, L. The vibrational spectrum of PdCO isolated in solid argon. Chem. Phys. 1999, 250, 187-197.

(11) Andrews, L.; Moskovits, M. Chemistry and Physics of Matrix-Isolated species, North Holland, Amsterdam, 1986.

(12) Clemmer, D. E.; Honma, K.; Koyano, I. Kinetics of excited-state titanium( $\left.a^{5} F\right)$ depletion by nitric oxide, oxygen, nitrous oxide, and nitrogen. J. Phys. Chem. 1993, 97, 11480-11488.

(13) Matsuda, Y.; Shin D. N.; Bernstein, E. R. On the copper oxide neutral cluster distribution in the gas phase: Detection through $355 \mathrm{~nm}$ and $193 \mathrm{~nm}$ multiphoton and $118 \mathrm{~nm}$ single photon ionization. $J$. Chem. Phys. 2004, 120, 4165-4171.

(14) Tremblay, B.; Manceron, L.; Gutsev, G.; Andrews, L., Partridge, H. Experimental and theoretical infrared spectra of $\mathrm{Co}_{2}$ CO. J. Chem. Phys. 2002, 117, 8479-8485.

(15) Tremblay, B.; Gutsev, G.L. ; Andrews, L. ; Manceron, L. Vibrational Spectrum and Structure of the $\mathrm{Fe}_{2} \mathrm{CO}$ Molecule. An Infrared Matrix Isolation and Density Functional Theory Study. J. Phys. Chem. A. 2002, 106, 10525-10531. 
(16) Xu, Q.; Jiang, L.; Tsumori, N. cyclo- $\mathrm{Ti}_{3}\left[\eta^{2}\left(\mu_{2}-\mathrm{C}, \mathrm{O}\right)\right]_{3}$ : A Side-on-Bonded Polycarbonyl Titanium Cluster with Potentially Antiaromatic Character. Angew. Chem. Int. Ed. 2005, 44, 4338-4342.

(17) Jiang, L.; Xu, Q. Observation of Anomalous $\mathrm{C}-\mathrm{O}$ Bond Weakening on Discandium and Activation Process to CO Dissociation. J. Am. Chem. Soc. 2005, 127, 42-43.

(18) Xu, Q.; Jiang, L.; Zou, R. Q. Infrared-Spectroscopic and Density-Functional-Theory Investigations of the LaCO, $\mathrm{La}_{2}\left[\eta^{2}\left(\mu_{2}-\mathrm{C}, \mathrm{O}\right)\right]$, and c-La $(\mu-\mathrm{C})(\mu-\mathrm{O})$ Molecules in Solid Argon. Chem. Eur. J. 2006, 12, 3226-3232.

(19) Jiang, L.; Xu, Q. nfrared Spectroscopic and Density Functional Theory Studies on the CO Dissociation by Scandium and Yttrium Dimers. J. Phys. Chem. A. 2006, 110, 5636-5641.

(20) Jiang, L.; Xu, Q. Infrared Spectra of the $(\mathrm{AgCO})_{2}$ and $\operatorname{Ag}_{n} \mathrm{CO}(\mathrm{n}=2-4)$ Molecules in Rare-Gas Matrices. J. Phys. Chem. A. 2006, 110, 11488-11493.

(21) Jiang, L.; Xu, Q. Reactions of Gold Atoms and Small Clusters with CO: Infrared Spectroscopic and Theoretical Characterization of $\mathrm{Au}_{\mathrm{n}} \mathrm{CO}(\mathrm{n}=1-5)$ and $\mathrm{Au}_{\mathrm{n}}(\mathrm{CO})_{2}(\mathrm{n}=1,2)$ in Solid Argon. J. Phys. Chem. A. 2005, 109, 1026-1032.

(22) Souvi, S. M.; Tremblay, B.; Perchard, J. P.; Alikhani, M. E. $\mathrm{Pd}_{2} \mathrm{~N}_{2}$ a proteiform molecule: Matrix isolation spectroscopy and density functional theory calculations. J. Chem. Phys. 2009, 130, 074304.

(23) Alikhani, M. E.; Souvi, S. M.; Ibrahim, M.; Tremblay, B. Spectra and structures of the $\mathrm{Pd}_{\mathrm{m}} \mathrm{CO}: \mathrm{An}$ Infrared Matrix Isolation and Density Functional study. J. Mol. Spectrosc. 2019, 361, 8-15.

(24) Souvi, S. M.; Berkaine, N.; Alikhani, M. E.; Manceron, L. Neon-matrix spectroscopic and theoretical studies of the reactivity of titanium dimer with diatomic ligands: comparison of reactions with nitrogen and carbon monoxide. Phys. Chem. Chem. Phys. 2009, 11, 9831-9839.

(25) Marzouk, A.; Bolvin, H. Reinhardt, P.; Manceron, L.; Perchard, J. P.; Tremblay, B.; Alikhani, M.E. A Combined Experimental and Theoretical Study of the $\mathrm{Ti}_{2}+\mathrm{N}_{2} \mathrm{O}$ Reaction. J. Phys. Chem. A. 2014, 118, $561-572$

(26) Zhang, N.; Luo, M.; Chi, C.; Wang, G.; Cui, J.; Zhou, M. Infrared Photodissociation Spectroscopy of Mass-Selected Heteronuclear Iron-Copper Carbonyl Cluster Anions in the Gas Phase. J. Phys. Chem. A. 2015, 119, 4142-4150. 
(27) Qu, H.; Kong, Fanchen.; Wang, G.; Zhou, M. Infrared Photodissociation Spectroscopy and theoretical study of Heteronuclear transition metal Carbonyl Cluster cations in the Gas Phase. J. Phys. Chem. A. 2016, 120, 7287-7293.

(28) Qu, H.; Kong, Fanchen.; Wang, G.; Zhou, M. Infrared Photodissociation Spectroscopy of Heterodinuclear iron-zinc and cobalt-zinc Carbonyl cation complexes. J. Phys. Chem. A. 2017, 121, $1627-1362$.

(29) Zhiling, L. ; Xie, H.; Qin, Z. ; Fan, H. ; and Tang, Z. . Structural evolution of homoleptic heteronuclear copper-nickel carbonyl anions revealed using photoelectron velocity-map imaging, Inorg. Chem. 2014, 53, 10909-10916.

(30) Xie, H.; Zou, J. ; Yuan, Q., Fan, H. ; Tang, Z. and Jiang, L., Photoelectron velocity-map imaging and theoretical studies of heteronuclear metal carbonyls $\mathrm{MNi}(\mathrm{CO})_{3}{ }^{-}(\mathrm{M}=\mathrm{Mg}, \mathrm{Ca}, \mathrm{Al}) \mathrm{J}$. Chem. Phys. 2016, $144,124303$.

(31) Zou, J. ; Xie, H.; Yuan, Q., Zhang, J., Fan, H. ; Tang, Z. and Jiang, L., Probing the bonding of CO to hereronuclear grouip 4 metal-nickel clusters by photoelectron spectroscopy, Phys. Chem. Chem. Phys. 2017, 19, 9790-9797.

(32) Zhiling, L.; Xie, H.; Zou, J.; Fan, H.; and Tang, Z., Observation of promoted C-O bond weakening on the heterometallic nickel-silver: photoelectron velocity-map imaging spectroscopy of $\operatorname{AgNi}(\mathrm{CO})_{\mathrm{n}}, \mathrm{J}$. Chem. Phys. 2017, 146, 244316.

(33) Zhang, J., Xie, H.; Li, G., Kong, X., Fan, H. and Jiang, L., Photoelectron velocity-map imaging and theoretical studies of heterotrinuclear metal carbonyls $\mathrm{V}_{2} \mathrm{Ni}(\mathrm{CO})_{\mathrm{n}}{ }^{-}(\mathrm{n}=6-10) \mathrm{J}$. Phys. Chem. A 2018, $122,53-59$.

(34) Yuan, Q.; Zhang, J.; Zou, J.; Fan, H.; Jiang, L.; and Xie, H., Photoelectron velocity map imaging spectroscopic and theoretical study of heteronuclear vanadium-nickel anions $\mathrm{VNi}(\mathrm{CO})_{\mathrm{n}}{ }^{-}(\mathrm{n}=2-16) \mathrm{J}$. Chem. Phys. 2018, 149, 144305.

(35) Danset, D.; Manceron, L., Mid- and near-IR electronic absorption spectrum of CoO isolated in solid neon. Vibronic data for low-lying electronic states. J. Phys. Chem. A 2003, 107, 11324-11330. 
(36) Feller, D., The Role of Databases in Support of Computational Chemistry Calculations. J. Comp. Chem. 1996, 17, 1571-1586.

(37) Schuchardt, K. L., Didier, B.T., Elsethagen, T., Sun, L., Gurumoorthi, V., Chase, J., Li, J., and Windus, T.L. Basis Set Exchange: A Community Database for Computational Sciences. J. Chem. Inf. Model. 2007, 47, 1045-1052, 2007.

(38) M. J. Frisch, G. W. Trucks, H. B. Schlegel et al. Gaussian 09, Revision D.01, Gaussian Inc.: Wallingford CT, (2009).

(39) R.F.W. Bader, Atoms in Molecules: A Quantum Theory, Clarendon, Oxford, U.K. 1990.

(40) AIMAll (Version 17.11.14), Todd A. Keith, TK Gristmill Software, Overland Park KS, USA, 2017 (aim.tkgristmill.com).

(41) Manceron, L.; Alikhani, M. E., Infrared spectrum and structure of $\mathrm{Ni}(\mathrm{CO})_{2}$. A matrix isolation and DFT study. Chem. Phys. 1999, 244, 215-226. 